\title{
Phytochemical Constituents, Antioxidant Activity, and Toxicity Assessment of the Aerial Part Extracts from the Infraspecific Taxa of Matthiola fruticulosa (Brassicaceae) Endemic to Sicily
}

\author{
Maria Fernanda Taviano 1,*(i), Emilia Cavò ${ }^{1,2}$, Vivienne Spadaro ${ }^{3}$, Francesco Maria Raimondo 4 , \\ Vincenzo Musolino ${ }^{5}$, Francesco Cacciola ${ }^{6}{ }^{(0)}$, Yassine Oulad El Majdoub ${ }^{1}$, Luigi Mondello ${ }^{1,7,8,9}{ }^{\circ}$, \\ Concetta Condurso ${ }^{10}$, Fabrizio Cincotta ${ }^{10}$, Antonella Verzera ${ }^{10}$ and Natalizia Miceli ${ }^{1}$ (i)
}

check for

updates

Citation: Taviano, M.F.; Cavò, E.; Spadaro, V.; Raimondo, F.M.; Musolino, V.; Cacciola, F.; El Majdoub, Y.O.; Mondello, L.; Condurso, C.; Cincotta, F.; et al. Phytochemical Constituents, Antioxidant Activity, and Toxicity Assessment of the Aerial Part Extracts from the Infraspecific

Taxa of Matthiola fruticulosa

(Brassicaceae) Endemic to Sicily. Molecules 2021, 26, 4114. https:// doi.org/10.3390/molecules26144114

Academic Editors: Petras

Rimantas Venskutonis and Marcello Iriti

Received: 2 June 2021

Accepted: 30 June 2021

Published: 6 July 2021

Publisher's Note: MDPI stays neutral with regard to jurisdictional claims in published maps and institutional affiliations.

Copyright: (c) 2021 by the authors. Licensee MDPI, Basel, Switzerland. This article is an open access article distributed under the terms and conditions of the Creative Commons Attribution (CC BY) license (https:// creativecommons.org/licenses/by/ $4.0 /)$.
1 Department of Chemical, Biological, Pharmaceutical and Environmental Sciences, University of Messina, Viale Palatucci, 98168 Messina, Italy; ecavo@unime.it (E.C.); youladelmajdoub@unime.it (Y.O.E.M.); lmondello@unime.it (L.M.); nmiceli@unime.it (N.M.)

2 Foundation "Prof. Antonio Imbesi", University of Messina, Piazza Pugliatti 1, 98122 Messina, Italy

3 Department STEBICEF/Section of Botany, Anthropology and Zoology, University of Palermo, Via Archirafi 38, 90123 Palermo, Italy; vivienne.spadaro@unipa.it

4 PLANTA/Research, Documentation and Training Center, Via Serraglio Vecchio 28, 90123 Palermo, Italy; raimondo@centroplantapalermo.org

5 Department of Health Sciences, University “Magna Graecia” of Catanzaro, V. Europa, Località Germaneto, 88100 Catanzaro, Italy; v.musolino@unicz.it

6 Department of Biomedical, Dental, Morphological and Functional Imaging Sciences, University of Messina, Via Consolare Valeria, 98125 Messina, Italy; cacciolaf@unime.it

7 Chromaleont s.r.l., c/o Department of Chemical, Biological, Pharmaceutical and Environmental Sciences, University of Messina, Viale Palatucci, 98168 Messina, Italy

8 BeSep s.r.l., c/o Department of Chemical, Biological, Pharmaceutical and Environmental Sciences, University of Messina, Viale Palatucci, 98168 Messina, Italy

9 Department of Sciences and Technologies for Human and Environment, University Campus Bio-Medico of Rome, Via Àlvaro del Portillo 21, 00128 Rome, Italy

10 Department of Veterinary Sciences, University of Messina, Viale Palatucci, 98168 Messina, Italy; concetta.condurso@unime.it (C.C.); fabrizio.cincotta@unime.it (F.C.); antonella.verzera@unime.it (A.V.)

* Correspondence: mtaviano@unime.it; Tel.: +39-090-6766478

Abstract: In a project designed to investigate the specific and infraspecific taxa of Matthiola endemic to Sicily (Italy) as new potential sources of bioactive compounds in this work, the infraspecific taxa of Matthiola fruticulosa were studied, namely, subsp. fruticulosa and subsp. coronopifolia. HPLCPDA/ESI-MS and SPME-GC/MS analyses of hydroalcoholic extracts obtained from the aerial parts of the two subspecies led to the detection of 51 phenolics and 61 volatile components, highlighting a quite different qualitative-quantitative profile. The antioxidant properties of the extracts were explored through in vitro methods: 1,1-diphenyl-2-picrylhydrazyl (DPPH), reducing power and $\mathrm{Fe}^{2+}$ chelating activity assays. The results of the antioxidant tests showed that the extracts possess a different antioxidant ability: particularly, the extract of $M$. fruticulosa subsp. fruticulosa exhibited higher radical scavenging activity than that of subsp. coronopifolia $\left(\mathrm{IC}_{50}=1.25 \pm 0.02 \mathrm{mg} / \mathrm{mL}\right.$ and $2.86 \pm 0.05 \mathrm{mg} / \mathrm{mL}$ ), which in turn displayed better chelating properties $\left(\mathrm{IC}_{50}=1.49 \pm 0.01 \mathrm{mg} / \mathrm{mL}\right.$ and $0.63 \pm 0.01 \mathrm{mg} / \mathrm{mL}$ ). Lastly, Artemia salina lethality bioassay was performed for toxicity assessment. The results of the bioassay showed lack of toxicity against brine shrimp larvae for both extracts. The data presented indicate the infraspecific taxa of M. fruticulosa as new and safe sources of antioxidant compounds.

Keywords: native plants; Sicily; natural resource; Matthiola fruticulosa; chemical composition; biological activity 


\section{Introduction}

Brassicaceae plants have been an interesting research topic for years due to their chemical composition characterized by the presence of a variety of bioactive metabolites with valuable potential applications in improving nutrition and human health [1].

In recent years, our research team has focused on the study of taxa that grow spontaneously in Sicily (Italy) included in the Brassicaceae family, with the aim of discovering new sources of bioactive compounds that could be used in the pharmaceutical, nutraceutical, and cosmetic fields. In a previous article, we reported the characterization of the phenolic and volatile components and the in vitro antioxidant properties of the aerial part hydroalcoholic extract of M. incana subsp. incana (L.) R. Br. [2]. Based on the promising results obtained, it seemed interesting to extend our research to the other specific and infraspecific taxa comprised in the genus Matthiola R. Br. endemic to Sicily. In particular, the infraspecific taxa of Matthiola fruticulosa (L.) Maire were selected for the current study.

Matthiola fruticulosa (L.) Maire (synonyms: Cheiranthus fruticulosus L., Matthiola tristis (L.) R. Br.) is a perennial species that reaches up to $60 \mathrm{~cm}$ in height, sparsely pubescent to densely white tomentose, woody at the base. The leaves are linear or oblong, entire to sinuate-pinnatifid, and the flowers are gathered in terminal racemes with yellowish to purplish-violet petals. The fruit is a siliqua, erect or patent, more or less cylindrical [3-5].

Matthiola fruticulosa is native to Southern Europe (Southeastern Europe: Albania, Bulgaria, Croatia, Greece, Italy, Macedonia, Montenegro, Serbia; Southwestern Europe: France, Portugal, Spain), Northern Africa (Algeria, Libya, Morocco, Tunisia), and Western Asia (Cyprus, Turkey) [3,5,6].

In the "Flora Europaea" and "Flora Hellenica", as well as in the consulted taxonomic database "The Plant List", three different subspecies are indicated under M. fruticulosa: the nominal subspecies (i.e., subsp. fruticulosa), subsp. valesiaca (Gay ex Gaudin) P. W. Ball, and subsp. perennis (P. Conti) P. W. Ball $[5,7,8]$. On the other hand, in the latest edition of the "Flora d'Italia" only two infraspecific subdivisions are recognized for this taxon: the nominal subspecies, which prefers calcareous grounds, and the subsp. coronopifolia (Sm.) Giardina and Raimondo (synonyms: Cheiranthus coronopifolius Sm., M. tristis var. montana Lojac., M. tristis var. bicornis Lojac., M. fruticulosa var. tricornis Lojac.), which prefers clayey and marly substrates [3,9]. Both subspecies occur in Sicily, as reported in the "Checklist of the vascular flora of Sicily" by Raimondo et al. [4].

The use of M. fruticulosa as a folk remedy has been documented: actually, its utilization in traditional medicine in Libya for the treatment of kidney stones and piles has been reported [10]. Despite this, as far as we know, in the literature there are no bibliographic data about the phytochemical composition and the evaluation of the biological properties of this taxon, except for the not very recent characterization of a few glucosinolates in the seeds and aerial parts of $M$. fruticulosa collected in Spain [11].

These premises prompted us to design a study aimed at defining the phytochemical profile and the antioxidant properties of the hydroalcoholic extracts obtained from the aerial parts of both M. fruticulosa infraspecific taxa growing wild in Sicily, namely, subsp. fruticulosa and subsp. coronopifolia. A comprehensive insight into the qualitative-quantitative profile of the phenolic and the volatile constituents contained in the extracts was achieved by HPLC-PDA/ESI-MS and SPME-GC/MS analyses. Three different in vitro methods, which are based on different mechanisms, were used to assess the antioxidant activity. Lastly, the brine shrimp (Artemia salina Leach) lethality bioassay was utilized to evaluate the toxicity of the extracts.

Both infraspecific taxa of $M$. fruticulosa were found to be safe sources of bioactive compounds with antioxidant properties significantly different from a phytochemical point of view. 


\section{Results and Discussion}

\subsection{Phytochemical Investigations}

\subsubsection{Determination of Polyphenolic Compounds by HPLC-PDA/ESI-MS}

The polyphenolic characterization of the hydroalcoholic extracts of the aerial parts of the two subspecies of $M$. fruticulosa is reported here for the first time. In Figure 1, the HPLC-PDA chromatograms $(\lambda=280 \mathrm{~nm})$ of the polyphenolic compounds occurring in the extracts of $M$. fruticulosa subsp. fruticulosa (A) and subsp. coronopifolia (B) are shown. A total of 51 compounds were detected, 31 in $M$. fruticulosa subsp. fruticulosa and 22 in subsp. coronopifolia (Table 1). Among them, 20 phenolic compounds were tentatively identified in M. fruticulosa subsp. fruticulosa according to retention times, PDA, MS, and literature data, 11 belonging to a class of flavonoids and 9 to phenolic acids; on the other hand, 11 compounds were characterized in $M$. fruticulosa subsp. coronopifolia, 6 flavonoids, and 5 phenolic acids. The identified flavonoid compounds belong to a class of flavonols, namely, quercetin, kaempferol, and isorhamnetin, and of flavones, namely, luteolin and its derivative isoorientin, while the phenolic acids are benzoic acids, hydroxybenzoic acid and syringic acid, and cinnamic acids, sinapic acid and ferulic acid. Except for peak n. 6 in M. fruticulosa subsp. fruticulosa, the rest of the polyphenolic compounds occurred in a glycosylated form.

In addition to polyphenols, 4-(methylthio)but-3-enyl glucosinolate (glucoraphenin) and its isomer (peaks n. 3 and n. 4) were detected in traces in the extract of $M$. fruticulosa subsp. fruticulosa only. The presence of this glucosinolate compound in a $70 \%$ methanol extract of $M$. fruticulosa aerial parts collected in Spain was previously reported by Gmelin and Kjær [12].

Interestingly, from the comparison of the phenolics detected in the two subspecies, a quite different profile was highlighted since no compounds in common were found.

Regarding quantitative determination, the total amount of polyphenols identified in the extract of $M$. fruticulosa subsp. fruticulosa was found to be approximately three fold higher than that of subsp. coronopifolia $(151.6 \mathrm{mg} / \mathrm{g}$ extract and $51.8 \mathrm{mg} / \mathrm{g}$ extract, respectively), with the flavonoids being $91.7 \mathrm{mg} / \mathrm{g}$ extract and $33.5 \mathrm{mg} / \mathrm{g}$ extract and the phenolic acids $59.9 \mathrm{mg} / \mathrm{g}$ extract and $18.3 \mathrm{mg} / \mathrm{g}$ extract. In addition, peak $\mathrm{n}$. 36, feruloylhydroxyferuloyl-dihexoside, was the most abundant polyphenolic compound in M. fruticulosa subsp. fruticulosa $(26.74 \mathrm{mg} / \mathrm{g} \pm 2.48)$, whereas in $M$. fruticulosa subsp. coronopifolia, peak n. 30, kaempferol derivative, turned out to be the main component (11.93 $\mathrm{mg} / \mathrm{g} \pm 0.82)$.
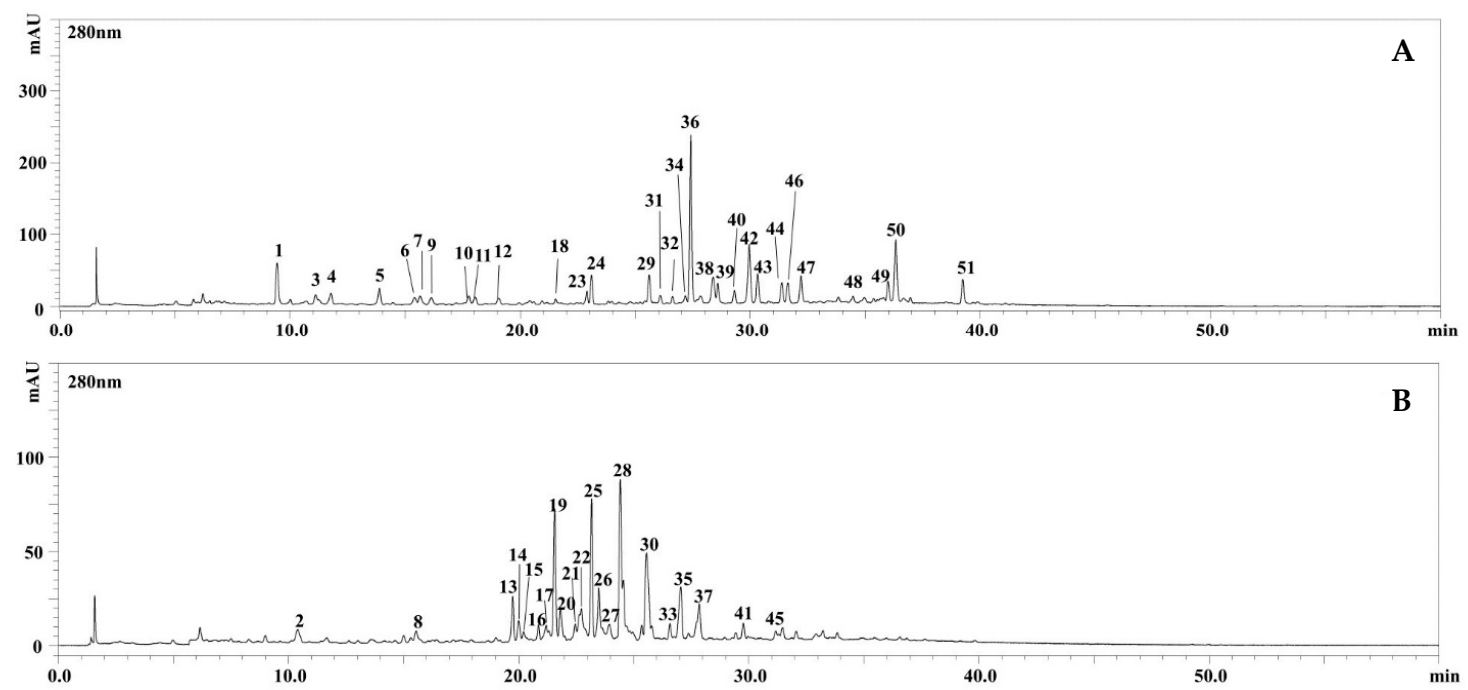

Figure 1. HPLC-PDA chromatograms of the polyphenolic compounds, extracted at $280 \mathrm{~nm}$ wavelength, of the hydroalcoholic extracts obtained from the aerial parts of M. fruticulosa subsp. fruticulosa (A) and subsp. coronopifolia (B). For peak identification, see Table 1. 


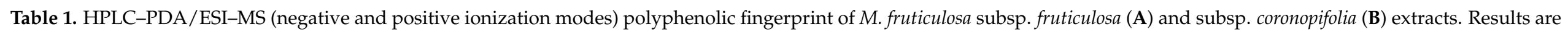
expressed as $\mathrm{mg} / \mathrm{g}$ extract \pm S.D. $(n=3)$.

\begin{tabular}{|c|c|c|c|c|c|c|c|}
\hline \multirow{2}{*}{$\mathbf{N}^{\mathbf{o}}$} & \multirow{2}{*}{$\underset{(\min )}{t_{R}}$} & \multirow{2}{*}{$\begin{array}{c}\mathrm{UV}_{\max } \\
(\mathrm{nm})\end{array}$} & \multirow{2}{*}[\mathbf{M}-\mathbf{H}]{$^{-}$} & \multirow{2}{*}[\mathbf{M}+\mathbf{H}]{$^{+}$} & \multirow{2}{*}{$\begin{array}{c}\text { Tentative } \\
\text { Identification }\end{array}$} & \multicolumn{2}{|c|}{ mg/g Extract } \\
\hline & & & & & & A & B \\
\hline 1 & 9.3 & 260 & 299 & - & Hydroxybenzoic acid-hexoside & $6.21 \pm 1.73$ & n.d. \\
\hline 2 & 10.4 & 276 & 359 & - & Syringic acid-hexoside & n.d. & $1.64 \pm 0.03$ \\
\hline 3 & 11.0 & 264,297 & 418 & - & 4-(methylthio)but-3-enyl glucosinolate & n.q. & n.d. \\
\hline 4 & 11.7 & 293 & 418 & - & 4-(methylthio)but-3-enyl glucosinolate isomer & n.q. & n.d. \\
\hline 5 & 13.8 & 257,295 & 387 & - & Unknown & n.q. & n.d. \\
\hline 6 & 15.3 & 277 & 325 & - & 5-hydroxyferuloylmalate & $1.71 \pm 0.30$ & n.d. \\
\hline 7 & 15.5 & 315 & 289 & - & Unknown & n.q. & n.d. \\
\hline 8 & 15.6 & 308 & 413 & - & Unknown & n.d. & n.q. \\
\hline 9 & 16.0 & 232 & 329 & - & Unknown & n.q. & n.d. \\
\hline 10 & 17.6 & 330 & 517 & - & Feruloyl-dihexoside & $3.01 \pm 0.67$ & n.d. \\
\hline 11 & 17.9 & 329 & 355 & - & Ferulic acid-dihexoside & $3.23 \pm 0.78$ & n.d. \\
\hline 12 & 19.0 & 330 & 385 & - & Sinapoylhexoside & $3.91 \pm 0.72$ & n.d. \\
\hline 13 & 19.7 & $269_{\mathrm{sh}}, 329$ & 437 & - & Unknown & n.d. & n.q. \\
\hline 14 & 20.0 & $267_{\text {sh }}, 314$ & $725,433,285$ & 595 & Kaempferol derivative & n.d. & $1.82 \pm 0.01$ \\
\hline 15 & 20.2 & $267_{\text {sh }}, 328$ & 411 & - & Unknown & n.d. & n.q. \\
\hline 16 & 20.9 & $268_{\mathrm{sh}}, 329$ & 423,379 & - & Unknown & n.d. & n.q. \\
\hline 17 & 21.2 & 337 & 371 & - & Hydroxyferuloyl-hexoside & n.d. & $1.62 \pm 0.07$ \\
\hline 19 & 21.6 & $269_{\mathrm{sh}}, 328$ & $595,440,285$ & 339 & Kaempferol-dihexoside & n.d. & $10.99 \pm 0.26$ \\
\hline 20 & 21.8 & $269_{\mathrm{sh}}, 318$ & $739,579,285$ & - & Kaempferol-trihexoside & n.d. & $3.23 \pm 0.15$ \\
\hline 21 & 22.5 & 329 & 739,579 & 595 & Sinapoylhydroxyferuloyl-dihexoside & n.d. & $1.53 \pm 0.18$ \\
\hline 22 & 22.6 & 349 & 741,301 & - & Quercetin derivative & n.d. & $3.03 \pm 0.37$ \\
\hline 23 & 22.8 & 266,337 & 185 & - & Unknown & n.q. & n.d. \\
\hline 24 & 23.0 & 329 & 739,579 & 595 & Sinapoylhydroxyferuloyl-dihexoside isomer & $4.93 \pm 1.25$ & n.d. \\
\hline 25 & 23.2 & $268_{\text {sh }}, 336$ & 387,501 & 438 & Unknown & n.d. & n.q. \\
\hline 26 & 23.5 & $269_{\mathrm{sh}}, 314$ & 387 & - & Unknown & n.d. & n.q. \\
\hline 27 & 23.9 & 311 & 251 & - & Unknown & n.d. & n.q. \\
\hline 28 & 24.4 & 266,349 & 725 & 433 & Dihydroxyferuloyl-hexoside & n.d. & $10.83 \pm 0.04$ \\
\hline 29 & 25.5 & 255,350 & 725 & 433 & Dihydroxyferuloyl-hexoside isomer & $5.63 \pm 1.30$ & n.d. \\
\hline 30 & 25.6 & 330 & $755,515,435,285$ & - & Kaempferol derivative & n.d. & $11.93 \pm 0.82$ \\
\hline 31 & 26.0 & 353 & $579,303,285$ & 449 & Kaempferol-trihexoside & $2.74 \pm 1.79$ & n.d. \\
\hline 32 & 26.5 & 266,346 & 458 & - & Unknown & n.q. & n.d. \\
\hline
\end{tabular}


Table 1. Cont

\begin{tabular}{|c|c|c|c|c|c|c|c|}
\hline \multirow{2}{*}{$\mathbf{N}^{\mathbf{o}}$} & \multirow{2}{*}{$\underset{(\min )}{t_{R}}$} & \multirow{2}{*}{$\begin{array}{c}\mathrm{UV}_{\max } \\
(\mathrm{nm})\end{array}$} & \multirow{2}{*}[\mathbf{M}-\mathbf{H}]{$^{-}$} & \multirow{2}{*}[\mathbf{M}+\mathbf{H}]{$^{+}$} & \multirow{2}{*}{$\begin{array}{c}\text { Tentative } \\
\text { Identification }\end{array}$} & \multicolumn{2}{|c|}{ mg/g Extract } \\
\hline & & & & & & A & B \\
\hline 33 & 26.6 & 338 & 593,447 & - & Isoorientin-hexoside & n.d. & $2.76 \pm 0.68$ \\
\hline 34 & 27.0 & 352 & 771,301 & 303 & Quercetin-p-coumaroylhexoside & $3.65 \pm 0.47$ & n.d. \\
\hline 35 & 27.0 & 339 & 695 & 433 & Unknown & n.d. & n.q. \\
\hline 36 & 27.3 & 266,346 & $709,563,431$ & 287 & Feruloylhydroxyferuloyl-dihexoside & $26.74 \pm 2.48$ & n.d. \\
\hline 37 & 27.9 & 318 & $725,563,593$ & - & Dihydroxyferuloyl-dihexoside isomer & n.d. & $2.77 \pm 0.52$ \\
\hline 38 & 28.2 & 265,347 & $755,609,285$ & - & Kaempferol derivative & $10.12 \pm 3.28$ & n.d. \\
\hline 39 & 28.5 & 329 & 739,579 & - & Sinapoylhydroxyferuloyl-dihexoside isomer & $4.74 \pm 0.88$ & n.d. \\
\hline 40 & 29.2 & 254,351 & 593,285 & 463,287 & Luteolin-dihexoside & $3.75 \pm 2.36$ & n.d. \\
\hline 41 & 29.8 & 329 & 613,518 & - & Unknown & n.d. & n.q. \\
\hline 42 & 29.8 & 265,348 & $785,755,593,285$ & 287 & Kaempferol-feruloyldihexoside & $19.85 \pm 3.16$ & n.d. \\
\hline 43 & 30.2 & 265,348 & $785,755,593,285$ & - & Kaempferol-feruloyldihexoside isomer & $10.25 \pm 2.86$ & n.d. \\
\hline 44 & 31.3 & 265,345 & 593,285 & 287 & Kaempferol-dihexoside & $6.16 \pm 0.85$ & n.d. \\
\hline 45 & 31.5 & 329 & 759,449 & - & Unknown & n.d. & n.q. \\
\hline 46 & 31.5 & 254,352 & $623,447,315$ & 479,317 & Isorhamnetin-dihexoside & $12.96 \pm 3.94$ & n.d. \\
\hline 47 & 32.1 & 254,352 & $623,447,315$ & 479,317 & Isorhamnetin-dihexoside isomer & $17.63 \pm 1.85$ & n.d. \\
\hline 48 & 34.4 & 330 & $447,409,285$ & 181 & Kaempferol-hexoside & $3.14 \pm 0.26$ & n.d. \\
\hline 49 & 35.9 & 330 & 535 & 495,287 & Unknown & n.q. & n.d. \\
\hline 51 & 39.2 & 310 & 674 & 339 & Unknown & n.q. & n.d. \\
\hline
\end{tabular}

n.d.: not detected; n.q.: not quantified. 
Comparing the polyphenolic profiles of the two subspecies here analyzed with that of the aerial part extract of $M$. incana subsp. incana previously investigated, substantial qualiquantitative differences were highlighted [2]. Indeed, the total amount of polyphenols detected in the $M$. incana subsp. incana extract $(161.31 \mathrm{mg} / \mathrm{g}$ extract) was quite similar to that of $M$. fruticulosa subsp. fruticulosa and about three times higher than that of subsp. coronopifolia, with the flavonoids being the most representative group $(155.85 \mathrm{mg} / \mathrm{g}$ extract), while the two phenolic acids identified (i.e., vanillic and sinapic acids) occurred in small amounts. On the other hand, phenolic acids were contained in greater numbers in the extracts from the two subspecies of $M$. fruticulosa, accounting their amounts to be about one-third of the total phenols quantified for both of them.

\subsubsection{Identification of Volatile Compounds by SPME-GC/MS}

Table 2 reports the volatile profile of the hydroalcoholic extracts obtained from the aerial parts of M. fruticulosa subsp. fruticulosa and subsp. coronopifolia. As can be observed in the table, the 61 volatiles identified can be classified into several main groups: aldehydes (mainly with alkanals, 2-alkenals, and 2,4-alcadienals, although also aromatic), acids, alcohols (mainly unsaturated and branched), ketones, esters (mainly methyl esters), sulfides, nitriles, and terpenoids.

Table 2. Composition as volatile constituents and classes of substances of the hydroalcoholic extracts obtained from the aerial parts of M. fruticulosa subsp. fruticulosa and subsp. coronopifolia.

\begin{tabular}{|c|c|c|c|c|c|c|}
\hline \multirow{2}{*}{ Compound } & \multirow{2}{*}{$\begin{array}{l}\text { LRI * on } \\
\text { DB-5ms }\end{array}$} & \multirow{2}{*}{$\begin{array}{l}\text { LRI * on } \\
\text { VF-AXms }\end{array}$} & \multicolumn{2}{|c|}{$\begin{array}{l}\text { M. fruticulosa } \\
\text { Subsp. fruticulosa }\end{array}$} & \multicolumn{2}{|c|}{$\begin{array}{c}\text { M. fruticulosa } \\
\text { Subsp. coronopifolia }\end{array}$} \\
\hline & & & $\begin{array}{l}\text { Amount }^{\dagger} \\
X \pm \text { Dev St }\end{array}$ & $\begin{array}{l}\text { Percentage } \\
X \pm \text { Dev St }\end{array}$ & $\begin{array}{c}\text { Amount }^{\dagger} \\
X \pm \text { Dev St }\end{array}$ & $\begin{array}{l}\text { Percentage } \\
X \pm \text { Dev St }\end{array}$ \\
\hline \multicolumn{7}{|l|}{ Aldehydes } \\
\hline 2-Methylbutanal & 675 & 913 & $\_\S$ & - & $1262 \pm 143$ & $3.73 \pm 0.39$ \\
\hline Heptanal & 903 & 1198 & - & - & $51 \pm 7$ & $0.15 \pm 0.02$ \\
\hline (E)-2-Heptenal & 957 & 1338 & - & - & $396 \pm 43$ & $1.17 \pm 0.19$ \\
\hline Benzaldehyde & 962 & 1529 & $261 \pm 47$ & $0.22 \pm 0.02$ & $298 \pm 38$ & $0.88 \pm 0.11$ \\
\hline Octanal & 1004 & 1298 & $508 \pm 51$ & $0.43 \pm 0.05$ & $101 \pm 19$ & $0.30 \pm 0.05$ \\
\hline$(E, E)-2,4$-Heptadienal & 1014 & 1497 & - & - & $247 \pm 34$ & $0.73 \pm 0.14$ \\
\hline Phenylacetaldehyde & 1043 & 1640 & - & - & $213 \pm 37$ & $0.63 \pm 0.11$ \\
\hline Nonanal & 1105 & 1398 & $5554 \pm 939$ & $4.72 \pm 0.74$ & - & - \\
\hline (E)-2-Nonenal & 1161 & 1543 & $72 \pm 12$ & $0.06 \pm 0.01$ & - & - \\
\hline Decanal & 1206 & 1502 & $115 \pm 19$ & $0.10 \pm 0.02$ & $116 \pm 14$ & $0.34 \pm 0.06$ \\
\hline (E)-2-Decenal & 1263 & 1647 & - & - & $101 \pm 12$ & $0.30 \pm 0.05$ \\
\hline (Z)-9-Octadecenal & 2006 & 2693 & $242 \pm 42$ & $0.21 \pm 0.03$ & - & - \\
\hline All & & & $6752 \pm 385$ & $5.73 \pm 0.30$ & $2787 \pm 55$ & $8.24 \pm 0.16$ \\
\hline \multicolumn{7}{|l|}{ Acids } \\
\hline Benzoic acid & 1165 & 2433 & $522 \pm 60$ & $0.47 \pm 0.08$ & - & - \\
\hline Octanoic acid & 1174 & 2072 & $262 \pm 29$ & $0.22 \pm 0.04$ & $636 \pm 96$ & $1.88 \pm 0.31$ \\
\hline Nonanoic acid & 1269 & 2178 & $180 \pm 26$ & $0.15 \pm 0.02$ & $231 \pm 30$ & $0.68 \pm 0.09$ \\
\hline Decanoic acid & 1366 & 2284 & - & - & $205 \pm 36$ & $0.61 \pm 0.11$ \\
\hline All & & & $995 \pm 41$ & $0.84 \pm 0.05$ & $1072 \pm 62$ & $3.17 \pm 0.20$ \\
\hline \multicolumn{7}{|l|}{ Alcohols } \\
\hline (E)-2-Hepten-1-ol & 973 & 1515 & - & - & $409 \pm 78$ & $1.21 \pm 0.19$ \\
\hline 1-Octen-3-ol & 980 & 1452 & - & - & $2719 \pm 342$ & $8.04 \pm 1.09$ \\
\hline 2-Ethyl-1-hexanol & 1029 & 1489 & $164 \pm 20$ & $0.14 \pm 0.02$ & - & - \\
\hline (E)-2-Octen-1-ol & 1068 & 1617 & - & - & $244 \pm 35$ & $0.72 \pm 0.14$ \\
\hline 1-Octanol & 1072 & 1561 & - & - & $393 \pm 71$ & $1.16 \pm 0.21$ \\
\hline 2-Methyl-1-octanol & 1100 & - & - & - & $148 \pm 27$ & $0.44 \pm 0.08$ \\
\hline All & & & $164 \pm 20$ & $0.14 \pm 0.02$ & $3914 \pm 161$ & $11.58 \pm 0.51$ \\
\hline \multicolumn{7}{|l|}{ Ketones } \\
\hline 4-Methyl-2-pentanone & 736 & 1010 & - & - & $487 \pm 90$ & $1.44 \pm 0.23$ \\
\hline 2-Hexanone & 790 & 1083 & - & - & $265 \pm 36$ & $0.78 \pm 0.15$ \\
\hline
\end{tabular}


Table 2. Cont.

\begin{tabular}{|c|c|c|c|c|c|c|}
\hline \multirow{2}{*}{ Compound } & \multirow{2}{*}{$\begin{array}{l}\text { LRI * on } \\
\text { DB-5ms }\end{array}$} & \multirow{2}{*}{$\begin{array}{l}\text { LRI * on } \\
\text { VF-AXms }\end{array}$} & \multicolumn{2}{|c|}{$\begin{array}{c}\text { M. fruticulosa } \\
\text { Subsp. fruticulosa }\end{array}$} & \multicolumn{2}{|c|}{$\begin{array}{c}\text { M. fruticulosa } \\
\text { Subsp. coronopifolia }\end{array}$} \\
\hline & & & $\begin{array}{c}\text { Amount }^{\dagger} \\
X \pm \text { Dev St }^{-}\end{array}$ & $\begin{array}{l}\text { Percentage } \\
X \pm \text { Dev St }\end{array}$ & $\begin{array}{c}\text { Amount }^{\dagger} \\
X \pm \text { Dev St }\end{array}$ & $\begin{array}{l}\text { Percentage } \\
X \pm \text { Dev St }\end{array}$ \\
\hline 4-Methyl-3-penten-2-one & 801 & 1132 & $2267 \pm 228$ & $1.92 \pm 0.39$ & $4097 \pm 746$ & $12.12 \pm 2.43$ \\
\hline Acetylacetone & 815 & 1196 & - & - & $278 \pm 50$ & $0.82 \pm 0.14$ \\
\hline 2-Heptanone & 891 & 1185 & - & - & $201 \pm 29$ & $0.60 \pm 0.09$ \\
\hline 3-Methyl-2-heptanone & 936 & 1210 & $446 \pm 77$ & $0.38 \pm 0.07$ & $499 \pm 77$ & $1.48 \pm 0.19$ \\
\hline Acetophenone & 1066 & 1656 & $249 \pm 39$ & $0.21 \pm 0.04$ & - & - \\
\hline Hexahydrofarnesyl acetone & 1844 & 2121 & $318 \pm 58$ & $0.27 \pm 0.04$ & $4835 \pm 717$ & $14.3 \pm 2.01$ \\
\hline All & & & $3279 \pm 125$ & $2.78 \pm 0.20$ & $10663 \pm 394$ & $31.54 \pm 1.20$ \\
\hline \multicolumn{7}{|l|}{ Esters } \\
\hline Methyl heptanoate & 1023 & 1293 & $693 \pm 136$ & $0.59 \pm 0.09$ & - & - \\
\hline Methyl benzoate & 1094 & 1628 & $6239 \pm 1218$ & $5.3 \pm 1.02$ & - & - \\
\hline Methyl octanoate & 1123 & 1394 & $363 \pm 65$ & $0.31 \pm 0.05$ & $94 \pm 10$ & $0.28 \pm 0.05$ \\
\hline Ethyl octanoate & 1196 & 1439 & $126 \pm 19$ & $0.11 \pm 0.01$ & $135 \pm 14$ & $0.40 \pm 0.05$ \\
\hline Methyl decanoate & 1323 & 1594 & $216 \pm 34$ & $0.18 \pm 0.03$ & $64 \pm 8$ & $0.19 \pm 0.03$ \\
\hline Ethyl 9-decenoate & 1386 & 1678 & $180 \pm 24$ & $0.15 \pm 0.03$ & $395 \pm 66$ & $1.17 \pm 0.19$ \\
\hline Ethyl decanoate & 1394 & 1639 & $1078 \pm 128$ & $0.92 \pm 0.14$ & $1193 \pm 216$ & $3.53 \pm 0.56$ \\
\hline $\begin{array}{l}\text { Fumaric acid, pent-4-en-2-yl } \\
\text { propyl ester }\end{array}$ & 1492 & - & $371 \pm 55$ & $0.32 \pm 0.05$ & $146 \pm 18$ & $0.43 \pm 0.08$ \\
\hline Ethyl dodecanoate & 1590 & 1840 & - & - & $60 \pm 8$ & $0.18 \pm 0.04$ \\
\hline Methyl tetradecanoate & 1726 & 1997 & - & - & $40 \pm 6$ & $0.12 \pm 0.01$ \\
\hline Methyl hexadecanoate & 1926 & 2199 & $264 \pm 39$ & $0.22 \pm 0.02$ & $192 \pm 35$ & $0.57 \pm 0.09$ \\
\hline Isopropyl hexadecanoate & 2023 & 2232 & - & - & $53 \pm 8$ & $0.16 \pm 0.03$ \\
\hline All & & & $9530 \pm 412$ & $8.09 \pm 0.35$ & $2373 \pm 73$ & $7.02 \pm 0.19$ \\
\hline \multicolumn{7}{|l|}{ Sulfur compounds } \\
\hline Dimethyl disulfide & 743 & 1082 & $855 \pm 111$ & $0.73 \pm 0.12$ & $855 \pm 137$ & $2.53 \pm 0.49$ \\
\hline Dimethyl trisulfide & 968 & 1391 & $80953 \pm 14196$ & $68.73 \pm 13.01$ & $539 \pm 97$ & $1.6 \pm 0.29$ \\
\hline Dimethyl tetrasulfide & 1215 & 1750 & $9554 \pm 1063$ & $8.11 \pm 1.29$ & - & - \\
\hline All & & & $91362 \pm 8219$ & $77.57 \pm 7.55$ & $1395 \pm 119$ & $4.13 \pm 0.40$ \\
\hline \multicolumn{7}{|l|}{ Nitriles } \\
\hline 4-Methylpentanenitrile & 840 & 1253 & - & - & $778 \pm 110$ & $2.3 \pm 0.47$ \\
\hline Hexanenitrile & 877 & 1308 & - & - & $333 \pm 61$ & $0.98 \pm 0.16$ \\
\hline Heptanenitrile & 978 & 1408 & $855 \pm 103$ & $0.73 \pm 0.09$ & - & - \\
\hline 4-(Methylthio)-butanenitrile & 1082 & 1806 & - & - & $1629 \pm 257$ & $4.79 \pm 0.85$ \\
\hline Benzyl nitrile & 1137 & 1893 & $409 \pm 66$ & $0.35 \pm 0.07$ & - & - \\
\hline All & & & $1264 \pm 87$ & $1.08 \pm 0.08$ & $2730 \pm 165$ & $8.08 \pm 0.57$ \\
\hline \multicolumn{7}{|l|}{ Terpenoids } \\
\hline Isophorone & 1126 & 1621 & - & - & $35 \pm 4$ & $0.10 \pm 0.01$ \\
\hline Cryptone & 1175 & 1675 & - & - & $289 \pm 37$ & $0.85 \pm 0.13$ \\
\hline Safranal & 1200 & 1649 & $891 \pm 127$ & $0.76 \pm 0.11$ & $208 \pm 39$ & $0.61 \pm 0.13$ \\
\hline$\beta$-Cyclocitral & 1220 & 1626 & $246 \pm 49$ & $0.21 \pm 0.03$ & $179 \pm 33$ & $0.53 \pm 0.09$ \\
\hline Pulegone & 1233 & 1637 & - & - & $166 \pm 22$ & $0.49 \pm 0.07$ \\
\hline Thymoquinone & 1250 & - & - & - & $171 \pm 19$ & $0.50 \pm 0.07$ \\
\hline $\begin{array}{l}\text { 2-Isopropyl-5-methyl-3- } \\
\text { cyclohexen-1-one }\end{array}$ & 1255 & - & - & - & $6605 \pm 1113$ & $19.54 \pm 3.76$ \\
\hline Carvacrol & 1291 & 2225 & - & - & $89 \pm 14$ & $0.26 \pm 0.04$ \\
\hline Geranylacetone & 1447 & 1857 & - & - & $86 \pm 13$ & $0.26 \pm 0.05$ \\
\hline All & & & $1136 \pm 96$ & $0.97 \pm 0.08$ & $7827 \pm 372$ & $23.15 \pm 1.26$ \\
\hline \multicolumn{7}{|l|}{ Hydrocarbons } \\
\hline 9-Octadecene & 1744 & 1795 & $554 \pm 80$ & $0.47 \pm 0.07$ & - & - \\
\hline 9-Eicosene & 1948 & 1914 & $280 \pm 38$ & $0.24 \pm 0.04$ & $50 \pm 7$ & $0.15 \pm 0.03$ \\
\hline All & & & $834 \pm 63$ & $0.71 \pm 0.06$ & $50 \pm 7$ & $0.15 \pm 0.03$ \\
\hline \multicolumn{7}{|l|}{ Others } \\
\hline All & & & $2463 \pm 368$ & $2.09 \pm 0.42$ & $995 \pm 179$ & $2.94 \pm 0.58$ \\
\hline
\end{tabular}

${ }^{*}$ Linear retention indexes calculated according to the Van Den Dool and Kratz equation; ${ }^{\dagger}$ peak area arbitrary scale; ${ }^{\S}$ not detected. 
As regards M. fruticulosa subsp. fruticulosa, the extract of the aerial parts was constituted mainly of sulfides (primarily dimethyl trisulfide and dimethyl tetrasulfide), which accounted for more than $77 \%$ of all volatiles. Among the other chemical classes, esters $(8.09 \%)$, aldehydes $(5.73 \%)$, and ketones $(2.78 \%)$ were the most represented, with methyl benzoate, nonanal, and 4-methyl-3-penten-2-one as the main compounds in the three classes, respectively. These five volatiles, namely, dimethyl trisulfide, dimethyl tetrasulfide, methyl benzoate, nonanal, and 4-methyl-3-penten-2-one, accounted for more than $88 \%$ of the volatile fraction of the $M$. fruticulosa subsp. fruticulosa extract.

The extract of the M. fruticulosa subsp. coronopifolia aerial parts showed a volatile profile in which ketones $(31.54 \%)$ and terpenes $(23.15 \%)$ prevailed, although the other classes were also well represented, ranging between $3.17 \%$ (acids) and $11.58 \%$ (alcohols). The main volatile compounds were 2-isopropyl-5-methyl-3-cyclohexen-1-one among terpenoids; hexahydrofarnesyl acetone, 4-methyl-3-penten-2-one, and 4-methyl-2-pentanone among ketones; 1-octen-3-ol among alcohols; 4-(methylthio)-butanenitrile and 4-methylpentanenitrile among nitriles; 2-methylbutanal among aldehydes; ethyl decanoate among esters; and dimethyl disulfide and octanoic acid among sulfides and acids, respectively.

Figure 2 shows the normalized percentage composition, as classes of substances, of the two subspecies of $M$. fruticulosa, highlighting considerable differences between them.

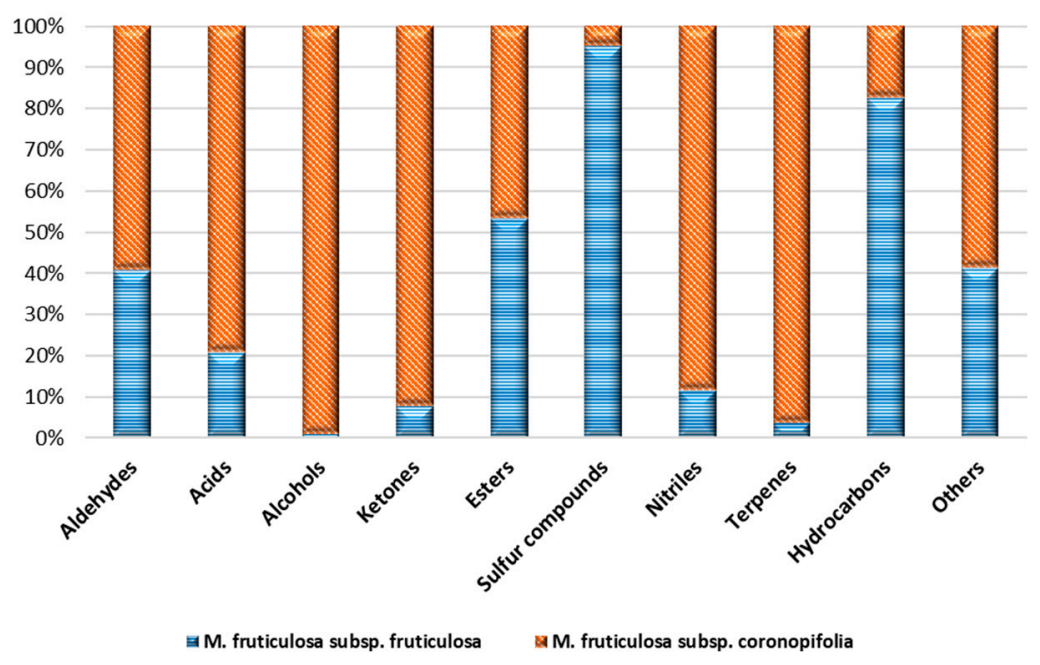

Figure 2. Normalized percentage composition, as classes of substances, of the volatile profile of $M$. fruticulosa subsp. fruticulosa and subsp. coronopifolia extracts.

In plants, several biosynthetic pathways occur, leading to a wide range of volatile organic compounds as secondary metabolites; thus, differences in the volatile profiles of different plants may reflect differences in their metabolic pathways. These differences have been observed in plants of the same species and even in different cultivars of the same subspecies [13]. The volatile compounds identified in the samples of M. fruticulosa subsp. fruticulosa and subsp. coronopifolia can be classified into terpenoids, carotenoid derivatives, fatty acid derivatives, amino acid derivatives, and benzenoid compounds.

The terpenoids safranal, $\beta$-cyclocitral, isophorone, and geranylacetone derive from the enzymatic degradation of carotenoids; the first two compounds were present in both subspecies, whereas the others only in subsp. coronopifolia, in any case at a low percentage. The other terpenoid compounds were detected only in the extract of M. fruticulosa subsp. coronopifolia, and all of them were oxygenated monoterpenes; these compounds have not been reported previously among volatiles of Matthiola species. Terpenoids in plants originate from two distinct metabolic pathways: the cytosolic mevalonic acid pathway (MVA) and the plastidial methylerythritol phosphate pathway (MEP). Isopentenyl pyrophosphate (IPP) and dimethylallyl pyrophosphate (DMAPP) are the end products in both pathways and are the precursors of a very large number of compounds by numer- 
ous enzyme-catalyzed reactions, including cyclization, hydroxylation, dehydrogenation, oxidation and/or reduction, and isomerization.

Aldehydes, alcohols, and esters, containing 6 to 10 carbon atoms, originate from unsaturated fatty acids through the lipoxygenase pathway. In particular, linoleic and linolenic acid are the precursors of the so-called green leaf volatiles, namely, $\mathrm{C} 6$ aldehydes, alcohols, and their ester. Linoleic acid is responsible also for the formation of 1-octen-3-one and 1-octen-3-ol, whereas nonanal, 1-nonanol, heptanal, and 1-heptanol are formed from oleic and palmitoleic acids. Among fatty acid derivative compounds, nonanal was the main volatile in subsp. fruticulosa, whereas 1-octen-3-ol was the most abundant in subsp. coronopifolia, highlighting possible differences between the two subspecies in both their fatty acid composition and the set of lipoxygenases.

Nitriles are among the amino-acid-derivative compounds. In fact, amino acids are the precursors of glucosinolates, a group of sulfur-containing secondary metabolites characterizing Brassicaceae vegetables; from the glucosinolate hydrolysis, through the action of the myrosinase enzyme, isothiocyanates, nitriles, and thiocyanates may arise. In both subspecies of $M$. fruticulosa, only nitriles were detected, with a higher percentage in subsp. coronopifolia, where 4-(methylthio)-butanenitrile was the most abundant compound, followed by 4-methylpentanenitrile. 4-(Methylthio)-butanenitrile originates from glucoerucin, which has been identified as the main glucosinolate in $M$. fruticulosa seeds [11]. The absence of isothiocyanates suggests that in our samples the hydrolysis of glucosinolates is altered in favor of nitriles; many factors can modify the activity of myrosinase, favoring nitrile formation [14], such as the presence of ferrous ions, nitrile-specific proteins, acidic conditions, and, according to Wieczorek and Jelen [13], also frozen-thawed processes of the vegetable tissue.

The only sulfur compounds detected in the extracts of M. fruticulosa subsp. fruticulosa and subsp. coronopifolia were sulfides (i.e., dimethyl disulfide, dimethyl trisulfide, and dimethyl tetrasulfide). Sulfides are derivative compounds of the S-alk(en)yl-l-cysteine pathway and occur very frequently in the volatile fraction of Brassicaceae family plants, even being the most abundant volatiles in M. incana subsp. incana and Brassica incana grown wild in Sicily [2,15] and in different cultivars of Brassica oleracea [13].

Benzenoid compounds are derived from $t$-cinnamic acid with the propyl side chain shortened by two carbon atoms via either a non- $\beta$-oxidative or a $\beta$-oxidative pathway, and the formation of benzaldehyde and benzoyl-CoA as intermediates for benzoic acid production [16]. Benzaldehyde and benzoic acid were detected only in the M. fruticulosa subsp. fruticulosa extract; moreover, methyl benzoate was also present, being the most abundant compound among esters.

Finally, hexahydrofarnesyl acetone was among the most abundant volatiles of the $M$. fruticulosa subsp. coronopifolia extract; hexahydrofarnesyl acetone, or phytone, is a ketone very common in plants that arises from the oxidative degradation of $(E)$-phytol, a diterpene alcohol that occurs as a side chain of chlorophyll a [17].

\subsection{Antioxidant Activity}

In the last decades, oxidative stress has been recognized to play a critical role in the pathogenesis of several diseases. This has significantly increased research studies aimed at discovering new plant sources of antioxidants. The Brassicaceae family encloses many plant species that are potential sources of antioxidant compounds, including some belonging to the Matthiola genus, as also demonstrated in recent studies on $M$. incana infraspecific taxa carried out by our research team [2,18-20].

In this work, the antioxidant properties of the extracts of M. fruticulosa subsp. fruticulosa and subsp. coronopifolia were established using three in vitro tests to evaluate the different mechanisms through which the diverse antioxidant compounds contained in the phytocomplexes could exert their effect: DPPH assay, based on the hydrogen atom transfer (HAT) and electron transfer (ET) mechanisms; reducing power, an electron transfer (ET)-based assay; and ferrous ion $\left(\mathrm{Fe}^{2+}\right)$ chelating activity assay. 
Figure 3A shows the results of the DPPH assay, utilized to determine the free scavenging ability of the extracts. Compared with the reference standard BHT, both extracts displayed lower activity in the range of concentrations tested, which increased with increasing dose. The extract of $M$. fruticulosa subsp. fruticulosa exhibited the best scavenging activity, reaching about $70 \%$ inhibition of the DPPH radical at the highest concentration tested. From the comparison of the calculated $\mathrm{IC}_{50}$ values, it was evidenced that the radical scavenging ability of the $M$. fruticulosa subsp. fruticulosa extract, showing an $\mathrm{IC}_{50}$ of $1.25 \pm 0.02 \mathrm{mg} / \mathrm{mL}$, was approximately 2.3 -fold higher than that of the subsp. coronopifolia extract $\left(\mathrm{IC}_{50}=2.86 \pm 0.05 \mathrm{mg} / \mathrm{mL}\right)$. Comparing the free radical scavenging activity of the M. fruticulosa subsp. fruticulosa extract with that highlighted in other Matthiola species, the result showed an activity higher than that of the hydroalcoholic extracts $(80 \% \mathrm{MeOH})$ of the aerial parts from the Matthiola incana infraspecific taxa endemic to Sicily, whose antioxidant properties had previously been investigated under the same experimental conditions, namely, $M$. incana subsp. incana, $\mathrm{IC}_{50}=2.32 \pm 0.24 \mathrm{mg} / \mathrm{mL}$; subsp. rupestris, $\mathrm{IC}_{50}=1.73 \pm 0.02 \mathrm{mg} / \mathrm{mL}$ and $2.60 \pm 0.01 \mathrm{mg} / \mathrm{mL}$; and subsp. pulchella, $\mathrm{IC}_{50}=3.69 \pm 0.14 \mathrm{mg} / \mathrm{mL}[2,18]$. On the other hand, Abdelshafeek et al. [20] reported a lower $\mathrm{IC}_{50}$ value $(0.49 \mathrm{mg} / \mathrm{mL})$ for a hydroalcoholic extract $(80 \% \mathrm{MeOH})$ obtained by maceration from the aerial parts of $M$. longipetala subsp. longipetala collected in Libya. The results of the evaluation of the reducing power of the extracts of the two subspecies of M. fruticulosa, determined through the $\mathrm{Fe}^{3+}-\mathrm{Fe}^{2+}$ transformation method, showed that both extracts displayed mild activity compared with the standard BHT. This result agrees with those previously reported for the extracts of the aerial parts from the $M$. incana infraspecific taxa $[2,18]$. As shown in Figure 3B, the extracts exhibited similar reducing power, dose dependent, although the calculated ASE/mL values indicated greater reducing efficacy for the extract of subsp. coronopifolia $(18.61 \pm 0.06 \mathrm{mg} / \mathrm{mL})$ than that of subsp. fruticulosa $(38.17 \pm 1.14 \mathrm{mg} / \mathrm{mL})$. Both extracts are less active than that of $M$. incana subsp. incana (ASE $/ \mathrm{mL}=12.28 \pm 0.42 \mathrm{mg} / \mathrm{mL}$ ), which showed the best reducing power among the infraspecific taxa of $M$. incana $[2,18]$.

In the $\mathrm{Fe}^{2+}$ chelating activity assay, performed by evaluating the inhibiting effect on the $\mathrm{Fe}^{2+}$-ferrozine complex formation, both extracts of the two subspecies of $M$. fruticulosa showed good chelating properties, dose dependent, although lower than those of the reference standard EDTA (Figure 3C). Contrary to what has been observed in the other antioxidant assays, the extract of $M$. fruticulosa subsp. coronopifolia displayed the best chelating activity, reaching about $75 \%$ inhibition at the highest concentration tested. This was confirmed also by a comparison of the $\mathrm{IC}_{50}$ values calculated for the extracts, which indicated that the chelating efficacy of $M$. fruticulosa subsp. coronopifolia $(0.63 \pm 0.01$ $\mathrm{mg} / \mathrm{mL}$ ) was approximately 2.5 -fold higher than that of $M$. fruticulosa subsp. fruticulosa $(1.49 \pm 0.01 \mathrm{mg} / \mathrm{mL})$. The chelating activity of the extract of $M$. fruticulosa subsp. coronopifolia was close to that previously found for that of $M$. incana subsp. incana $\left(\mathrm{IC}_{50}=0.53 \pm\right.$ $0.02 \mathrm{mg} / \mathrm{mL}$ ), the most effective among those from the infraspecific taxa of $M$. incana [2,18].

The results of the antioxidant tests clearly indicate that the extracts of the two subspecies of M. fruticulosa possess different antioxidant ability; in fact, the extract of $M$. fruticulosa subsp. fruticulosa exhibited higher radical scavenging activity than that of subsp. coronopifolia; conversely, the latter displayed better chelating properties than the former.

Among plant secondary metabolites, polyphenols represent the most important group of antioxidant compounds. Flavonoids and phenolic acids, the largest classes of plant phenolics, have been shown to be effective antioxidants in several in vitro and in vivo investigations [21-23]. The higher radical scavenging properties of the extract of M. fruticulosa subsp. fruticulosa seem to be related to the greater content of flavonoids and phenolic acids detected by HPLC-PDA/ESI-MS analysis, both present in quantities about three times higher than those of subsp. coronopifolia. Regarding the chelating properties, which are greater for $M$. fruticulosa subsp. coronopifolia, although the partial involvement of the phenolic constituents detected in the extracts cannot be ruled out, it is assumed that they may depend on other antioxidant phytochemicals. 

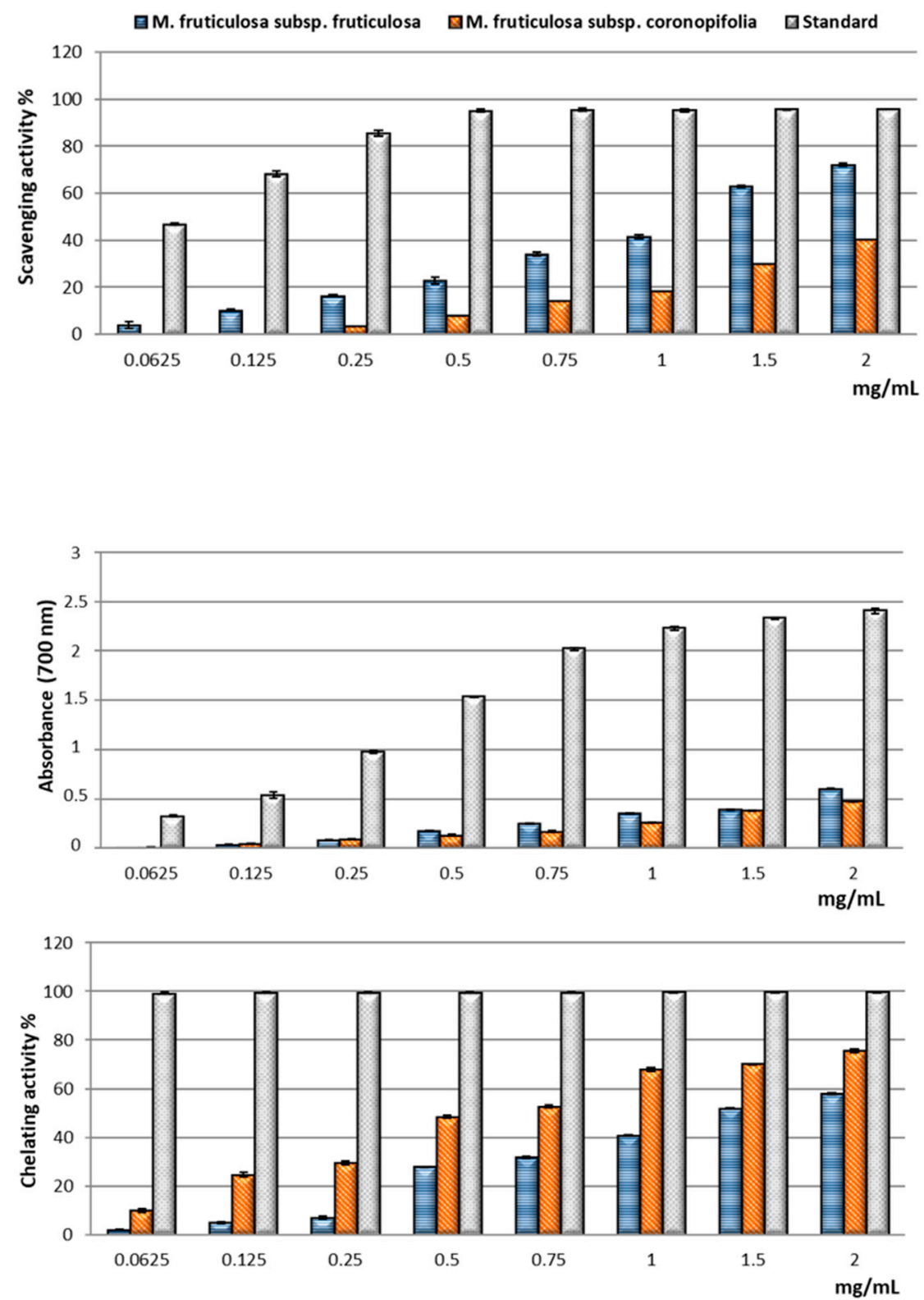

Figure 3. Free radical scavenging activity (DPPH assay) (A), reducing power (B), and ferrous ion chelating activity $(\mathbf{C})$ of the hydroalcoholic extracts obtained from the aerial parts of $M$. fruticulosa subsp. fruticulosa and subsp. coronopifolia. Reference standard: BHT (A,B), EDTA (C). Values are expressed as the mean $\pm \operatorname{SD}(n=3)$.

\subsection{Artemia salina Leach Lethality Bioassay}

Artemia salina Leach (brine shrimp) is a small crustacean widely utilized as a model organism in the toxicity assessment of plant extracts [24]. The brine shrimp lethality bioassay has been applied as an alternative method for the preliminary estimation of toxicity because it shows several advantages, such as rapidity, cost-effectiveness, ease of handling and maintenance under laboratory conditions, and adaptability to various testing conditions [25].

The results of the bioassay showed the absence of toxicity against brine shrimp larvae for both extracts of the $M$. fruticulosa subspecies. Indeed, the median lethal concentration values were found to be above $1000 \mu \mathrm{g} / \mathrm{mL}$, thus indicating their potential safety based on Clarkson's toxicity criterion [26]. The obtained results agree with those reported for the hydroalcoholic extracts of the aerial parts from the $M$. incana infraspecific taxa previously investigated, which were tested under the same experimental conditions [2,18]. 


\section{Materials and Methods}

\subsection{Chemicals and Reagents}

LC-MS-grade water $\left(\mathrm{H}_{2} \mathrm{O}\right)$, acetonitrile $(\mathrm{ACN})$, gallic acid, catechin, chlorogenic acid, apigenin, luteolin, rutin, kaempferol, and quercetin were obtained from Merck Life Science (Merck KGaA, Darmstadt, Germany). LC-MS-grade formic acid was purchased from Riedel-de Haën (Seelze, Germany). Methanol (MeOH) was purchased from Carlo Erba (Milan, Italy). Unless indicated otherwise, all chemicals were purchased from SigmaAldrich (Milan, Italy).

\subsection{Plant Material and Extraction Procedure}

The aerial parts of the Matthiola fruticulosa subspecies were collected in Sicily (Italy): M. fruticulosa subsp. fruticulosa (L.) Maire was picked in May 2019 in the locality of Polizzi Generosa, Contrada Pietà (Palermo), on a dolomitic lithosol, about $1200 \mathrm{~m}$ (a.s.l., above sea level), and M. fruticulosa subsp. coronopifolia (Sm.) Giardina and Raimondo in the locality of Sutera (Caltanissetta), on chalky cliffs, about $400 \mathrm{~m}$ (a.s.l.), in June 2019. Voucher specimens were identified by Prof. F.M. Raimondo, PLANTA/Center for Research, Documentation and Training (Palermo), and Prof. V. Spadaro, University of Palermo, and have been deposited to the Herbarium Mediterraneum of the University of Palermo, Italy (PAL-Gr) (voucher numbers: Raimondo \& Spadaro n. 03/19; Schimmenti n. 05/19).

After harvesting, the aerial parts of the two subspecies were immediately frozen; then after lyophilization, the plant material was subjected to a preventive maceration with $80 \%$ $\mathrm{MeOH}(1: 10 w / v)$ for $150 \mathrm{~min}$. The extraction was performed with $80 \% \mathrm{MeOH}(1: 10 w / v)$ in an ultrasonic bath at $50{ }^{\circ} \mathrm{C}$ for $15 \mathrm{~min}$ three times; then the filtrates were pooled and evaporated to dryness by a rotavapor. The yields of the extracts, referring to $100 \mathrm{~g}$ of lyophilized plant material, were $20.38 \%$ and $19.83 \%$ for $M$. fruticulosa subsp. fruticulosa and subsp. coronopifolia, respectively.

\subsection{Phytochemical Investigations}

\subsubsection{Identification of Phenolic Compounds by HPLC-PDA/ESI-MS}

The analyses were carried out using a Shimadzu HPLC system (Milan, Italy) equipped with a CBM-20A controller, LC-20AD pumps, a DGU-20A3 degasser, a SIL-20AC autosampler, an SPD-M20A photodiode array detector (PDA), and a triple quadrupole mass analyzer (LCMS-8050, Shimadzu, Kyoto, Japan), equipped with an ESI interface, in positive and negative ionization modes. Data acquisition was performed by Shimadzu LabSolutions software ver. 5.91 .

Samples and sample preparation: An amount of $20 \mathrm{mg}$ of M. fruticulosa subsp. fruticulosa and subsp. coronopifolia extracts was dissolved in $1 \mathrm{~mL}$ of $\mathrm{MeOH}$.

Chromatographic conditions: Analyses were carried out on an Ascentis Express C18, $15 \mathrm{~cm} \times 4.6 \mathrm{~mm}$ I.D. with a particle size of $2.7 \mu \mathrm{m}$ (Merck Life Science, Merck KGaA, Darmstadt, Germany). The injection volume was $5 \mu \mathrm{L}$, the mobile phase consisted of water/formic acid (99.9:0.1, v/v) (solvent A) and ACN/formic acid (99.9:0.1, v/v) (solvent B), and the linear gradient profile was as follows: $0 \mathrm{~min}, 0 \% \mathrm{~B} ; 5 \mathrm{~min}, 5 \% \mathrm{~B} ; 15 \mathrm{~min}, 10 \% \mathrm{~B}$; $30 \mathrm{~min}, 20 \% \mathrm{~B} ; 60 \mathrm{~min}, 50 \% \mathrm{~B} ; 70 \mathrm{~min}, 100 \% \mathrm{~B} ; 71 \mathrm{~min}, 0 \% \mathrm{~B}$. The flow rate was $1 \mathrm{~mL} / \mathrm{min}$, and it was split to $0.2 \mathrm{~mL} / \mathrm{min}$ prior to MS detection.

$P D A$ conditions: The wavelength range was $200-400 \mathrm{~nm}$, and the chromatograms were extracted at a wavelength of $280 \mathrm{~nm}$. Time constant was $0.08 \mathrm{~s}$, and the sample frequency was $40 \mathrm{~Hz}$.

MS conditions: The mass spectral range was $100-1000 \mathrm{~m} / \mathrm{z}$, the interval was $0.5 \mathrm{~s}$, the nebulizing gas $\left(\mathrm{N}_{2}\right)$ flow was $1.5 \mathrm{~L} / \mathrm{min}$, the interface temperature was $350{ }^{\circ} \mathrm{C}$, the heat block was $300{ }^{\circ} \mathrm{C}$, the DL temperature was $300{ }^{\circ} \mathrm{C}$, the DL voltage was $-34 \mathrm{~V}$, the probe voltage was $4.5 \mathrm{kV}$, the Qarray voltage was $1.0 \mathrm{~V}$, the RF voltage was $90 \mathrm{~V}$, and the detection gain was $1.0 \mathrm{kV}$.

Quantitative determination was performed using the calibration curves of six standards, namely, gallic acid, hydroxybenzoic acid, chlorogenic acid, luteolin, kaempferol, 
and quercetin. Standard calibration curves were prepared in the concentration range of $0.1-50 \mathrm{mg} / \mathrm{L}$ with five different concentration levels [27].

\subsubsection{Identification of Volatile Compounds by SPME-GC/MS}

Extraction (HS-SPME): The hydroalcoholic extracts of the aerial parts of $M$. fruticulosa subsp. fruticulosa and subsp. coronopifolia were analyzed for their volatile composition by HS-SPME-GC/MS.

An amount of $30.0 \mathrm{mg}$ of each dried extract was solubilized in $3.0 \mathrm{~mL}$ of saturated sodium chloride solution (final concentration of $10 \mathrm{mg} / \mathrm{mL}$ ) into a $7 \mathrm{~mL}$ vial, then closed with a "mininert" valve (Supelco, Bellefonte, PA, USA). The samples were extracted using a DVB/CAR/PDMS fiber with a 50/30 $\mu \mathrm{m}$ film thickness (Supelco, Bellefonte, PA, USA) following the method reported by Miceli et al. [2].

Analysis (GC/MS): The volatiles were analyzed by a Shimadzu GC 2010 Plus gas chromatograph coupled to a TQMS 8040 triple quadrupole mass spectrometer (Shimadzu, Milan, Italy) on two different capillary columns: (1) VF-WAXms, $60 \mathrm{~m}, 0.25 \mathrm{~mm}$ i.d., $0.25 \mu \mathrm{m}$ film thickness polar column (Agilent Technologies Italia S.p.A., Milan, Italy), and (2) DB- $5 \mathrm{~ms}, 30 \mathrm{~m}, 0.25 \mathrm{~mm}$ i.d., $0.25 \mu \mathrm{m}$ film thickness polar column (Agilent Technologies Italia S.p.A., Milan, Italy).

The conditions were as follows: injection mode, splitless; oven temperature, (1) $45^{\circ} \mathrm{C}$ held for $5 \mathrm{~min}$, then increased to $80^{\circ} \mathrm{C}$ at a rate of $10^{\circ} \mathrm{C} / \mathrm{min}$ and to $240{ }^{\circ} \mathrm{C}$ at $2{ }^{\circ} \mathrm{C} / \mathrm{min}$, held at $240{ }^{\circ} \mathrm{C}$ for $5 \mathrm{~min}$, for VF-WAXms column, and (2) $45^{\circ} \mathrm{C}$ increased to $160{ }^{\circ} \mathrm{C}$ at a rate of $3{ }^{\circ} \mathrm{C} / \mathrm{min}$ and to $260{ }^{\circ} \mathrm{C}$ at $10{ }^{\circ} \mathrm{C} / \mathrm{min}$, held at $260^{\circ} \mathrm{C}$ for $5 \mathrm{~min}$, for DB- $5 \mathrm{~ms}$ column; carrier gas, helium at a constant flow of $1 \mathrm{~mL} / \mathrm{min}$; transfer line temperature, $250{ }^{\circ} \mathrm{C}$; acquisition range, 40 to $360 \mathrm{~m} / z$; scan speed, 1250 . For the identification of the volatiles, mass spectral data, NIST 14 (NIST /EPA/NIH Mass Spectra Library, version 2.0, NIST Mass Spectrometry Data Center, National Institute of Standards and Technology, Gaithersburg, MD, USA) and FFNSC 3.0 databases, linear retention indexes (LRIs), literature data, and injection of the available standards were used [28].

\subsection{Antioxidant Activity}

\subsubsection{DPPH Assay}

The 1,1-diphenyl-2-picrylhydrazyl (DPPH) assay was used to determine the free radical scavenging activity of the hydroalcoholic extracts of $M$. fruticulosa subsp. fruticulosa and subsp. coronopifolia [29]. The extracts were tested in the range of $0.0625-2 \mathrm{mg} / \mathrm{mL}$ using butylated hydroxytoluene (BHT) as positive control. A $0.5 \mathrm{~mL}$ aliquot of each sample solution was added to $3 \mathrm{~mL}$ of DPPH methanol solution $(0.1 \mathrm{mM})$. The mixture was left at room temperature in the dark for $20 \mathrm{~min}$, and then absorbance was measured at $517 \mathrm{~nm}$ using a model UV-1601 spectrophotometer (Shimadzu). The results were obtained from the average of three independent experiments, and are reported as mean radical scavenging activity (\%) \pm standard deviation (SD) and mean $50 \%$ inhibitory concentration $\left(\mathrm{IC}_{50}\right) \pm \mathrm{SD}$.

\subsubsection{Reducing Power Assay}

The reducing power of the hydroalcoholic extracts of $M$. fruticulosa subsp. fruticulosa and subsp. coronopifolia was assessed by the $\mathrm{Fe}^{3+}-\mathrm{Fe}^{2+}$ transformation method [30]. The extracts were tested in the range of $0.0625-2 \mathrm{mg} / \mathrm{mL}$ using butylated hydroxytoluene (BHT) and ascorbic acid as positive controls. An amount of $1 \mathrm{~mL}$ of each sample solution was mixed with $2.5 \mathrm{~mL}$ of phosphate buffer $(0.2 \mathrm{M}, \mathrm{pH} 6.6)$ and $2.5 \mathrm{~mL}$ of $1 \%$ potassium ferricyanide. After incubation at $50{ }^{\circ} \mathrm{C}$ for $20 \mathrm{~min}$ and rapid cooling, $2.5 \mathrm{~mL}$ of $10 \%$ trichloroacetic acid was added. Finally, $2.5 \mathrm{~mL}$ of the supernatant was mixed with $2.5 \mathrm{~mL}$ of distilled water and $0.5 \mathrm{~mL}$ of $0.1 \%$ ferric chloride; then the mixture was incubated for $10 \mathrm{~min}$ at room temperature in the dark, and the optical density change was measured at $700 \mathrm{~nm}$. The results were obtained from the average of three independent experiments, and are expressed as mean absorbance values $\pm \mathrm{SD}$ and ascorbic acid equivalent $/ \mathrm{mL}$ $(\mathrm{ASE} / \mathrm{mL}) \pm \mathrm{SD}$. 


\subsubsection{Ferrous Ion $\left(\mathrm{Fe}^{2+}\right)$ Chelating Activity Assay}

The spectrophotometric measurement of the $\mathrm{Fe}^{2+}$-ferrozine complex was used to determine the $\mathrm{Fe}^{2+}$ chelating activity of the hydroalcoholic extracts of $M$. fruticulosa subsp. fruticulosa and subsp. coronopifolia according to the method previously reported by Decker and Welch [31]. The extracts were tested in the range of $0.0625-2 \mathrm{mg} / \mathrm{mL}$ using ethylenediaminetetraacetic acid (EDTA) as positive control. Briefly, $0.05 \mathrm{~mL}$ of $2 \mathrm{mM}$ ferrous chloride was added to $1 \mathrm{~mL}$ of sample solution and $0.5 \mathrm{~mL}$ of methanol. The reaction was initiated by the addition of $0.2 \mathrm{~mL}$ of $5 \mathrm{mM}$ ferrozine solution. After vigorous shaking, the mixture was incubated at room temperature in the dark for $10 \mathrm{~min}$; then the optical density change was measured spectrophotometrically at $562 \mathrm{~nm}$. The results were obtained from the average of three independent experiments and are reported as mean inhibition of the ferrozine $-\left(\mathrm{Fe}^{2+}\right)$ complex formation $(\%) \pm \mathrm{SD}$ and $\mathrm{IC}_{50} \pm \mathrm{SD}$.

\subsection{Artemia salina Leach Lethality Bioassay}

To establish the acute toxicity of the hydroalcoholic extracts of $M$. fruticulosa subsp. fruticulosa and subsp. coronopifolia, the brine shrimp (Artemia salina Leach) lethality bioassay was carried out according to the method of Meyer et al. [32]. Brine shrimp eggs were placed in a brine shrimp hatchery dish filled with sterile artificial seawater for $48 \mathrm{~h}$. After hatching, active nauplii free from eggshells were collected from the brighter portion of the hatchery dish and used for the assay. Ten brine shrimp larvae were incubated for $24 \mathrm{~h}$ at $25-28{ }^{\circ} \mathrm{C}$ in $5 \mathrm{~mL}$ of artificial seawater mixed with different amounts of the extracts $(10-1000 \mu \mathrm{g} / \mathrm{mL})$. Then, the surviving larvae were counted using a magnifying glass, and median lethal concentration $\left(\mathrm{LC}_{50}\right)$ values were determined by Litchfield and Wilcoxon's method. The assay was carried out in triplicate. The toxicity level of the extracts was assessed according to the toxicity scale reported by Clarkson et al. [26]; extracts giving $\mathrm{LC}_{50}$ values greater than $1000 \mu \mathrm{g} / \mathrm{mL}$ were considered nontoxic.

\section{Conclusions}

In summary, in this work we explored for the first time the phytochemical profile and the antioxidant properties of the hydroalcoholic extracts of the aerial parts of $M$. fruticulosa subsp. fruticulosa and subsp. coronopifolia endemic to Sicily (Italy). From the comparison of the extracts of the two infraspecific taxa of $M$. fruticulosa, a quite different qualitativequantitative profile of both phenolic and volatile compounds was highlighted, as well as a diverse antioxidant ability. It is interesting to note, in fact, that the extract of $M$. fruticulosa subsp. fruticulosa exhibited much higher radical scavenging activity, while that of subsp. coronopifolia was shown to be a better source of metal chelating antioxidants. Furthermore, the lack of toxicity against brine shrimp larvae indicates the potential safety of the extracts.

Overall, the data presented here improve the knowledge of the taxa included in the Matthiola genus, also indicating the infraspecific taxa of $M$. fruticulosa endemic to Sicily as new and safe sources of bioactive compounds, which increases the number of Brassicaceae plants hitherto known for their health-promoting properties. The present findings pave the way for new studies to further investigate the antioxidant properties of these taxa and to evaluate their potential protective effect against diseases related to oxidative stress.

Author Contributions: Conceptualization, M.F.T., V.S., F.M.R., and N.M.; investigation, M.F.T., E.C., V.M., F.C. (Francesco Cacciola), Y.O.E.M., C.C., F.C. (Fabrizio Cincotta), and N.M.; resources, V.S. and F.M.R.; data curation, M.F.T., F.C. (Francesco Cacciola), L.M., C.C., A.V., and N.M.; writing-original draft preparation, M.F.T., F.C. (Francesco Cacciola), C.C., and N.M.; writing-review and editing, M.F.T., V.S., F.M.R., L.M., A.V., and N.M. All authors have read and agreed to the published version of the manuscript.

Funding: This research received no external funding.

Data Availability Statement: The data presented in this study are available on request from the corresponding author. 
Acknowledgments: Emilia Cavò thanks the Foundation "Prof. Antonio Imbesi" for the fellowship. The authors are thankful to Shimadzu and Merck Life Science Corporation for their continuous support.

Conflicts of Interest: The authors declare no conflict of interest.

Sample Availability: Samples of the compounds are not available from the authors.

\section{References}

1. Favela-González, K.M.; Hérnandez-Almanza, A.; De la Fuente-Salcido, N.M. The value of bioactive compounds of cruciferous vegetables (Brassica) as antimicrobials and antioxidants: A review. J. Food Biochem. 2020, 44, e13414. [CrossRef]

2. Miceli, N.; Cavò, E.; Ragusa, S.; Cacciola, F.; Dugo, P.; Mondello, L.; Marino, A.; Cincotta, F.; Condurso, C.; Taviano, M.F. Phytochemical characterization and biological activities of a hydroalcoholic extract obtained from the aerial parts of Matthiola incana (L.) R. Br. subsp. incana (Brassicaceae) growing wild in Sicily (Italy). Chem. Biodivers. 2019, 16, e1800677.

3. Pignatti, S. Matthiola R. Br. In Flora d'Italia; Edagricole: Milano, Italy, 2017; Volume 2, pp. 912-916. ISBN 8850652437.

4. Raimondo, F.M.; Domina, G.; Spadaro, V. Checklist of the vascular flora of Sicily. Quad. Bot. Amb. Appl. 2010, 21, 189-252.

5. Ball, P.W. Matthiola R. Br. In Flora Europaea; Tutin, T.G., Heywood, V.H., Burges, N.A., Moore, D.M., Valentine, D.H., Walters, S.M., Webb, D.A., Eds.; Cambridge University Press: Cambridge, UK, 1964; Volume I, pp. 279-280.

6. Marhold, K. Brassicaceae. Euro+Med Plantbase-The Information Resource for Euro-Mediterranean Plant Diversity. Available online: http:/ / www.emplantbase.org/home.html (accessed on 21 April 2021).

7. The Plant List. Version 1.1. 2013. Available online: http://www.theplantlist.org (accessed on 21 April 2021).

8. Livaniou-Tiniakou, A. Matthiola R. Br. In Flora Hellenica; Strid, A., Tan, K., Eds.; Koeltz Scientific Books: Königstein, Germany, 2002; Volume 2, pp. 265-268.

9. Giardina, G.; Raimondo, F.M.; Spadaro, V. A catalogue of plants growing in Sicily. Bocconea 2007, $20,5-582$.

10. El-Mokasabi, F.M.; Al-Sanousi, A.F.; El-Mabrouk, R.M. Taxonomy and ethnobotany of medicinal plants in eastern region of Libya. J. Environ. Sci. Toxicol. Food Technol. 2018, 12, 14-23.

11. Daxenbichler, M.E.; Spencer, G.F.; Carlson, D.G.; Rose, G.B.; Brinker, A.M.; Powell, R.G. Glucosinolate composition of seeds from 297 species of wild plants. Phytochemistry 1991, 30, 2623-2638. [CrossRef]

12. Gmelin, R.; Kjær, A. Glucosinolates in Matthiola fruticulosa and related species: A reinvestigation. Phytochemistry 1970, 9, 569-573. [CrossRef]

13. Wieczorek, M.N.; Jeleń, H.H. Volatile compounds of selected raw and cooked Brassica vegetables. Molecules 2019, $24,391$. [CrossRef]

14. Fenwick, G.R.; Heaney, R.K.; Mullin, W.J.; VanEtten, C.H. Glucosinolates and their breakdown products in food and food plants. CRC Crit. Rev. Food Sci. Nutr. 1983, 18, 123-201. [CrossRef] [PubMed]

15. Speranza, J.; Taviano, M.F.; Ragusa, S.; Condurso, C.; Cincotta, F.; Verzera, A.; Day-Walsh, P.; Kroon, P.; Miceli, N. Characterization of volatile components and in vitro inhibitory effect on gut microbial TMA production of the leaf hydroalcoholic extract of Brassica incana Ten. (Brassicaceae) growing wild in Sicily (Italy). In Proceedings of the 115th Congresso della Società Botanica Italiana, Online, 9-11 September 2020; p. 194.

16. Moerkercke, A.V.; Schauvinhold, I.; Pichersky, E.; Haring, M.A.; Schuurink, R.C. A plant thiolase involved in benzoic acid biosynthesis and volatile benzenoid production. Plant. J. 2009, 60, 292-302. [CrossRef]

17. Schulz, S.; Yildizhan, S.; Van Loon, J.J. The biosynthesis of hexahydrofarnesylacetone in the butterfly Pieris brassicae. J. Chem. Ecol. 2011, 37, 360-363. [CrossRef]

18. Miceli, N.; Cavò, E.; Spadaro, V.; Raimondo, F.M.; Ragusa, S.; Cacciola, F.; Oulad El Majdoub, Y.; Arena, K.; Mondello, L.; Condurso, C.; et al. Phytochemical profile and antioxidant activity of the aerial part extracts from Matthiola incana subsp. rupestris and subsp. pulchella (Brassicaceae) endemic to Sicily. Chem. Biodivers. 2021, 18, e2100167.

19. Taviano, M.F.; Miceli, N.; Acquaviva, R.; Malfa, G.A.; Ragusa, S.; Giordano, D.; Cásedas, G.; Les, F.; López, V. Cytotoxic, antioxidant, and enzyme inhibitory properties of the traditional medicinal plant Matthiola incana (L.) R. Br. Biology 2020, 9, 163. [CrossRef] [PubMed]

20. Abdelshafeek, K.A.; Abdelmohsen, M.M.; Hamed, A.; Shahat, A.A. Investigation of some chemical constituents and antioxidant activity extracts of Matthiola longipetala subsp. longipetala. Chem. Nat. Compd. 2013, 49, 539-543. [CrossRef]

21. Singh, D.P.; Verma, S.; Prabh, R. Investigations on antioxidant potential of phenolic acids and flavonoids: The common phytochemical ingredients in plants. J. Plant. Biochem. Physiol. 2018, 6, 1000219. [CrossRef]

22. Kasote, D.M.; Katyare, S.S.; Hegde, M.V.; Bae, H. Significance of antioxidant potential of plants and its relevance to therapeutic applications. Int. J. Biol. Sci. 2015, 11, 982-991. [CrossRef]

23. Fernandez-Panchon, M.S.; Villano, D.; Troncoso, A.M.; Garcia-Parrilla, M.C. Antioxidant activity of phenolic compounds: From in vitro results to in vivo evidence. Crit. Rev. Food Sci. Nutr. 2008, 48, 649-671. [CrossRef]

24. Ntungwe, N.E.; Domínguez-Martín, E.M.; Roberto, A.; Tavares, J.; Isca, V.M.S.; Pereira, P.; Cebola, M.-J.; Rijo, P. Artemia species: An important tool to screen general toxicity samples. Curr. Pharm. Des. 2020, 26, 2892-2908. [CrossRef] [PubMed]

25. Libralato, G.; Prato, E.; Migliore, L.; Cicero, A.M.; Manfra, L. A review of toxicity testing protocols and endpoints with Artemia spp. Ecol. Indic. 2016, 69, 35-49. [CrossRef] 
26. Clarkson, C.; Maharaj, V.J.; Crouch, N.R.; Grace, O.M.; Pillay, P.; Matsabisa, M.G.; Bhagwandin, N.; Smith, P.J.; Folb, P.I. In vitro antiplasmodial activity of medicinal plants native to or naturalised in South Africa. J. Ethnopharmacol. 2004, 92, 177-191. [CrossRef]

27. Oulad El Majdoub, Y.; Alibrando, F.; Cacciola, F.; Arena, K.; Pagnotta, E.; Matteo, R.; Micalizzi, G.; Dugo, L.; Dugo, P.; Mondello, L. Chemical characterization of three accessions of Brassica juncea L. extracts from different plant tissues. Molecules 2020, $25,5421$. [CrossRef] [PubMed]

28. Cincotta, F.; Verzera, A.; Tripodi, G.; Condurso, C. Non-intentionally added substances in PET bottled mineral water during the shelf-life. Eur. Food Res. Technol. 2018, 244, 433-439. [CrossRef]

29. Ohnishi, M.; Morishita, H.; Iwahashi, H.; Shitzuo, T.; Yoshiaki, S.; Kimura, M.; Kido, R. Inhibitory effects of chlorogenic acid on linoleic acid peroxidation and haemolysis. Phytochemistry 1994, 36, 579-583. [CrossRef]

30. Oyaizu, M. Studies on products of browning reaction: Antioxidative activities of products of browning reaction prepared from glucosamine. Jpn J. Nutr. Diet. 1986, 44, 307-315. [CrossRef]

31. Decker, E.A.; Welch, B. Role of ferritin as a lipid oxidation catalyst in muscle food. J. Agric. Food Chem. 1990, 38, 674-677. [CrossRef]

32. Meyer, B.N.; Ferrigni, N.R.; Putnam, J.E.; Jacobson, L.B.; Nichols, D.E.; McLaughlin, J.L. Brine shrimp: A convenient general bioassay for active plant constituents. Planta Med. 1982, 45, 31-34. [CrossRef] 